\title{
THE DETERMINATION OF TOTAL SULPHUR IN INDIA RUBBER
}

\author{
By C. E. Waters and J. B. Tuttle
}

What may be still described as the usual method for the determination of total sulphur in india rubber is the one first published by Henriques. ${ }^{1}$ The details of this method are too well known to require descrirtion here. In more recent years other methods have been advocated. Alexander ${ }^{2}$ used sodium peroxide to decompose the nitrogen peroxide addition-product of rubber. In the same year Esch ${ }^{3}$ recommended the use of Eschka's mixture and procedure for the determination of sulphur in coal. $\mathrm{He}$ also stated that the sodium-peroxide method gives good results.

Wagner ${ }^{4}$ published a slight modification of the method of Henriques, stating that much sulphur is lost by volatilization. He, therefore, made the nitric-acid solution alkaline with sodium hydroxide, transferred to a nickel crucible, added sodium carbonate and then evaporated to dryness. The oxidation was carried to completion by heating in an air-bath.

Pontio ${ }^{5}$ fused with manganese peroxide and a mixture of sodium and potassium carbonates. The results were about o. I per cent lower than by the method of Henriques. For the free sulphur ${ }^{6}$ he extracted with absolute alcohol, distilled off the solvent, oxidized with alkaline hydrogen peroxide, evaporated to dryness and fused in a silver crucible.

$1 \mathrm{Z}$. angew. Chemie, 12, p. $902 ; 1899$.

2 Gummi-Ztg., 18, p. 729; Z. angew. Chemie, 17, p. I799; 1904.

3 Chem.-Ztg., 28, p. 200; I904.

1 Gummi-Ztg., 21, p. 552; Chem. Abstr., 1, p. 1327; r907.

- Caoutchouc et Gutta-Percha, 6, p. 275r; Chem. Techn. Rep., 1909; 372.

6 Caoutchouc et Gutta-Percha, 5, p. 2 194; Chem. Abstr., 2, p. 3412; r908. 
A distinct departure from the usual methods is due to Hinrichsen, ${ }^{7}$ who oxidizes electrolytically in the presence of concentrated or fuming nitric acid.

Finally, Hübener ${ }^{8}$ devised a method intended to exclude insoluble mineral sulphates. The sample is boiled in a flask with concentrated nitric acid for some time, most of the acid is evaporated off on the steam-bath, and the oxidation completed by means of bromine and water.

One of the present writers, having frequent occasion to determine total sulphur in rubber, over a year ago made a number of comparative tests of different variations of the method of Henriques. The results obtained with two samples of rubber are given below $(\mathrm{I}-\mathrm{V})$. In all cases, $0.50 \mathrm{~g}$ of rubber was taken. All fusions were made over a flame of gasoline-air gas. The results are given as percentages of sulphur. All reagents were tested, and no determinations have been omitted.

I. Warmed $2 \frac{1}{2}$ hours in covered crucible with 25 cc conc. $\mathrm{HNO}_{3}$, allowed to stand 36 hours, evaporated nearly to dryness, added $\mathrm{Na}_{2} \mathrm{CO}_{3} \cdot \mathrm{KNO}_{3}$ mixture and fused as usual.

$\begin{array}{lcccc}\text { Sample } & \text { I } & \text { I } & 2 & 2 \\ \text { Sulphur } & 3.39 & 3.44 & 3.26 & 3.22\end{array}$

II. Added $\mathrm{HNO}_{3}$ and I cc $\mathrm{Br}$, let stand 36 hours without preliminary heating, evaporated, etc., as usual.

$\begin{array}{lcccc}\text { Sample } & \text { I } & \text { I } & 2 & 2 \\ \text { Sulphur } & 3.40 & 3.47 & 3.39 & 3.27\end{array}$

III. The same as II, but allowed to stand only I hour, heated with cover for 2 hours, evaporated and fused as usual.

$\begin{array}{ccccc}\text { Sample } & \text { I } & \text { I } & 2 & 2 \\ \text { Sulphur } & 3.3 \mathrm{I} & 3.35 & 3.04 & 3.09\end{array}$

IV. Only $\mathrm{HNO}_{3}$ added, digested at once on the steam-bath for 2 hours, evaporated and fused.

$\begin{array}{ccccc}\text { Sample } & \text { I } & \text { I } & 2 & 2 \\ \text { Sulphur } & 3.17 & 3.43 & 3.06 & 2.93\end{array}$

7 Chem.-Ztg., 33, p. 735; r909.

8 Gummi-Ztg., 24, pp. 213-214; Analyst, 35, pp. 266-267; 19ro. 
$\mathrm{V}$. Treated with I cc $\mathrm{Br}$ and $5 \mathrm{cc}_{2} \mathrm{O}$, let stand over night without heating, next morning evaporated off the $\mathrm{H}_{2} \mathrm{O}$, added $\mathrm{HNO}_{3}$, digested, evaporated and fused.

$\begin{array}{ccccc}\text { Sample } & \text { I } & \text { I } & 2 & 2 \\ \text { Sulphur } & 3 \cdot 7 \mathrm{I} & 3.65 & 3.37 & 3.38\end{array}$

In an attempt to obtain satisfactory results without fusion, some determinations were made some months later, without a knowledge of Hübener's paper. Half-gram portions of a sample of medium hard rubber were digested with nitric acid in flasks covered with watch glasses. In some cases bromine was added after the digestion with acid and, after standing half an hour, water was added and the flasks heated on the steam-bath. Finally the volume was brought to about I $75 \mathrm{cc}$, the solution heated, filtered, and a little sodium hydroxide added to the filtrate and wash-water. This was then evaporated to dryness, adding a little hydrochloric acid toward the end, taken up with very dilute hydrochloric acid, filtered and barium sulphate precipitated as usual. The results follow:

VI. Treated with $\mathrm{HNO}_{3}$ alone.

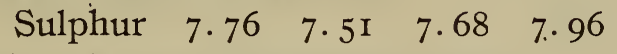

VII. Treated with $\mathrm{HNO}_{3}$, followed by $\mathrm{Br}$.

$$
\begin{array}{llllll}
\text { Sulphur } & 7.62 & 7.5 \mathrm{I} & 7.93 & 7.87 & 7.76
\end{array}
$$

All the precipitates obtained under VI and VII contained much lead.

After the method of Hübener was called to our attention some determinations were made on a sample of hard rubber containing no barium.

VIII. Hübener's method.

$$
\begin{array}{lllllll}
\text { Sulphur } & 4.79 & 3.91 & 5.23 & 4.02 & 4.3 \mathrm{I} & 4 . \mathrm{I} 3
\end{array}
$$

It is evident that widely different amounts of sulphur must have been retained in the insoluble residue in the form of lead sulphate.

IX. Total sulphur by method of Henriques.

$$
\text { Sulphur } 8.65 \quad 8.70
$$

X. Treated with $\mathrm{HNO}_{3}$, followed by $\mathrm{Br}$ and $\mathrm{H}_{2} \mathrm{O}$ and fused as usual.

$$
\begin{array}{lllllll}
\text { Sulphur } & 8.63 & 8.62 & 8.77 & 8.80 & 8.72 & 8.80
\end{array}
$$


It has recently been claimed by van't Kruys ${ }^{9}$ that when an excess of calcium chloride over the amount of sulphuric acid is present, only calcium sulphate is carried down with the barium sulphate, and the calcium salt can be converted into barium sulphate by digestion with strong hydrochloric acid, or aqua regia, and barium chloride. Several determinations were made to test this suggestion.

XI. Preliminary treatment as under $\mathrm{X}$, subsequent treatment as suggested by van't Kruys.
Sulphur
8.76
8.52
8.46
$8.74 \quad 8.78$
$8.75 \quad 8.77$

At this point, joint analyses of a fairly large sample of rubber were carried out by the present writers.

XII. Hübener's method. The sulphur in the insoluble residue was determined by fusion with soda-saltpeter mixture, extracting the melt with water, etc., as usual:

$\begin{array}{lllllllllll}S \text { in original filtrate } & 0.91 & 0.91 & 0.68 & 0.79 & 0.82 & 0.99 & \text { I.52 } & \text { I.I } 5 & \text { I.24 }\end{array}$ $\begin{array}{llllllllll}S \text { in insoluble residue } & 2.35 & 2.43 & 2.54 & 2.69 & 2.53 & 2.36 & \text { I.95 } & 2.3 \text { I } & 2.2 \text { I }\end{array}$

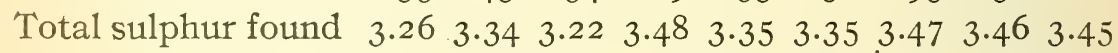
All the precipitates of barium sulphate from the original filtrates were found to contain lead when tested with dilute ammonium sulphide.

XIII. Treated with $\mathrm{HNO}_{3}$, allowed to stand over night, the acid driven off on the steam-bath, I cr $\mathrm{Br}$ and ro $\mathrm{cc} \mathrm{H}_{2} \mathrm{O}$ added; then the $\mathrm{H}_{2} \mathrm{O}$ and excess of $\mathrm{Br}$ driven off by heating. The residue was mixed with soda and saltpeter and fused as usual.

\section{Sulphur 3.4I $3.2 \mathrm{I}$}

XIV. The same as XIII, but the $\mathrm{HNO}_{3}$ not driven off before adding $\mathrm{Br}$.

\section{Sulphur $\quad 3.60 \quad 3.63 \quad 3.58 \quad 3.63 \quad 3.57$}

$\mathrm{XV}$. The same as XIII, but treatment with $\mathrm{Br}$ omitted.

$\begin{array}{llllllllll}\text { Sulphur } & 3.29 & 3.49 & 3.35 & 3.38 & 3.55 & 3.43 & 3.36 & 3.58 & 3.56\end{array}$

XVI. Treated first with bromine and water, allowed to stand over night without heating, then $\mathrm{Br}$ and $\mathrm{H}_{2} \mathrm{O}$ driven off on steambath, treated with $\mathrm{HNO}_{3}$, etc., and fused.

\section{$\begin{array}{llllll}\text { Sulphur } & 3.45 & 3.47 & 3.48 & 3.53 & 3.49\end{array}$}

XVII. The same as XVI, but excess $\mathrm{Br}$ and $\mathrm{H}_{2} \mathrm{O}$ not driven off before adding $\mathrm{HNO}_{3}$.

$$
\text { Sulphur } \quad 3.59 \quad 3.47 \quad 3.64
$$


XVIII. The method of Henriques, except that the $\mathrm{HNO}_{3}$ was saturated with $\mathrm{Br}$.

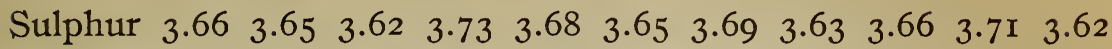

XIX. The same as XVIII, but followed by the treatment suggested by van't Kruys.

\section{$\begin{array}{lllll}\text { Sulphur } \quad 3.69 & 3.73 & 3.76 & 3.75\end{array}$}

In order to obtain a definite idea of the variations caused by differences in the preliminary treatment and in the conditions under which the barium sulphate is precipitated, a very dilute solution of sulphuric acid was made. In each of the following determinations, a 25 -cc portion was taken. The weights of the barium sulphate found were calculated as percentages of sulphur in $0.50 \mathrm{~g}$ of rubber, in order that the results might be more readily compared with the determinations above.

$\mathrm{XX}$. Direct precipitation with $\mathrm{BaCl}_{2}$ : The last two determinations were made with the addition of 2 cc of $\mathrm{I}: \mathrm{I} \mathrm{HCl}$, the first six without adding $\mathrm{HCl}$.

\section{Sulphur 3.I I 3.II 3.II 3.II 3.II 3.II 3.Io 3.II}

XXI. Evaporated off the water from $25 \mathrm{cc}$ of the dilute $\mathrm{H}_{2} \mathrm{SO}_{4}$, added the soda-saltpeter mixture and fused as usual.

\section{Sulphur 3.12 3.15 3.12}

XXII. Like XXI, but added $\mathrm{CaCl}_{2}$ to the solution of the melt before precipitating $\mathrm{BaSO}_{4}$, and treated the latter according to van't Kruys.

Sulphur $\quad 3.22 \quad 3.18 \quad 3.19$

XXIII. Like XXII, but did not digest the precipitated $\mathrm{BaSO}_{4}$ nor evaporate the filtrate to recover traces of dissolved $\mathrm{BaSO}_{4}$.

Sulphur 3.I3 3.I 2 3.I I

XXIV. Like XXI, but did not fuse. The solution was acidified with $\mathrm{HCl}$.

\section{Sulphur 3.17 3.19 3.16}

$\mathrm{XXV}$. Added $250 \mathrm{cc} \mathrm{H}_{2} \mathrm{O}$ and ro $\mathrm{cc}$ conc. $\mathrm{HCl}$ to $25 \mathrm{cc}$ dilute $\mathrm{H}_{2} \mathrm{SO}_{4}$, added $\mathrm{BaCl}_{2}$, digested two hours, poured off the supernatant liquid, digested the $\mathrm{BaSO}_{4}$ with I cc of Io per cent $\mathrm{BaCl}_{2}$ and $\mathrm{I} 5 \mathrm{cc} \mathrm{HCl}$ ( $\mathrm{I}: \mathrm{I})$. Diluted, filtered, evaporated the combined filtrates to dryness in platinum, took up with $50 \mathrm{cc}$ of slightly acidified $\mathrm{H}_{2} \mathrm{O}$ and collected the slight residue on the same filter. 
XXVI. Exactly neutralized $\mathrm{NaOH}$ solution with the dilute $\mathrm{H}_{2} \mathrm{SO}_{4}$, using phenolphthalein as indicator. After each addition of acid, the solution was heated in a platinum dish until the pink color no longer reappeared. Then evaporated to dryness, ignited gently, and weighed the $\mathrm{Na}_{2} \mathrm{SO}_{4}$.

$\begin{array}{lcc}\mathrm{H}_{2} \mathrm{SO}_{4} \text { used (cc) } & 75 \cdot 56 & 75 \cdot 55 \\ \mathrm{Na}_{2} \mathrm{SO}_{4} \text { found }(\mathrm{g}) & .2082 & .208 \mathrm{o} \\ \mathrm{BaSO}_{4} \text { equivalent to } \mathrm{Na}_{2} \mathrm{SO}_{4}(\mathrm{~g}) & .34 \mathrm{I} 97 & .34 \mathrm{I} 64 \\ \mathrm{BaSO}_{4} \text { equivalent to } 25 \mathrm{cc} \mathrm{H}_{2} \mathrm{SO}_{4}(\mathrm{~g}) & .1 \mathrm{I} 3 \mathrm{I} & . \mathrm{II} 30 \\ \text { Sulphur (calc. on } 0.5 \mathrm{~g} \text { rubber) } & 3 . \mathrm{II} & 3 . \mathrm{I} \mathrm{I}\end{array}$

XXVII. The same as XXVI, but used $\mathrm{NaHCO}_{3}$ instead of $\mathrm{NaOH}$.

$\mathrm{H}_{2} \mathrm{SO}_{4}$ used (cc)

$\mathrm{Na}_{2} \mathrm{SO}_{4}$ found (g)

$\mathrm{BaSO}_{4}$ equivalent to $\mathrm{Na}_{2} \mathrm{SO}_{4}(\mathrm{~g})$

$\mathrm{BaSO}_{4}$ equivalent to $25 \mathrm{cc}_{2} \mathrm{SO}_{4}(\mathrm{~g})$

Sulphur (calc. on $0.5 \mathrm{~g}$ rubber)
45.01

.1240

.20367

.II 31

3:I I
43.48

.1194 .19612 .1128

In order to test the completeness of the oxidation of sulphur by means of the nitric acid-bromine mixture, the following determinations were carried out.

XXVIII. Powdered sulphur crystals, digested in the cold with $20 \mathrm{cc} \mathrm{HNO}_{3}$ and an excess of $\mathrm{Br}$. Finally added $20 \mathrm{cc} \mathrm{H}_{2} \mathrm{O}$ and heated on the steam-bath for about two hours. Then evaporated nearly to dryness, took up with water, and precipitated with $\mathrm{BaCl}_{2}$.

$\begin{array}{rrrr}\text { Sulphur taken }(g) & 0.0483 & 0.0395 & 0.056 \mathrm{r} \\ \text { Sulphur found }(\mathrm{g}) & .048 \mathrm{r} & .0399 & .0563\end{array}$

XXIX. Powdered sulphur crystals treated at the same time as some of the samples of rubber. The exact methods are referred to in the table, the Roman numerals indicating the method employed.

Method

Sulphur taken (g)

Sulphur found $(g)$

Sulphur, per cent

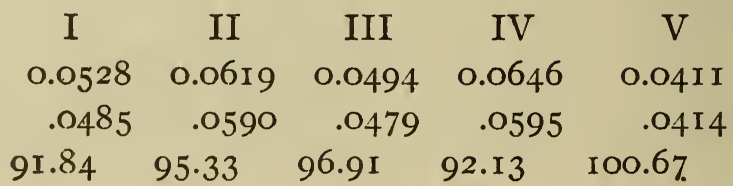


In the determinations by methods I to IV, part of the sulphur was not attacked by the nitric acid, nor by the sodium carbonate added before making the fusion. Part, at least, of this unattacked sulphur was seen to burn when the fusion was made.

As stated above (XII), the bariun sulphate precipitates representing soluble sulphates, etc., in the Hübener method, were found to contain lead. Lead sulphate dissolves slightly, and is, besides, partially decomposed by water, hydrobromic and nitric acids, etc. ${ }^{10}$ In order to get an idea of the amount of barium sulphate to be expected to result from the decomposition and solution of lead sulphate under the conditions of the Hübener method, some determinations were made. Lead sulphate was first prepared by precipitation from a hot, dilute nitric-acid solution of lead nitrate by means of a hot, dilute solution of sulphuric acid. It settled rapidly as a coarse-grained powder, which was washed by decantation with hot water, then in a Gooch crucible with hot water, followed by strong alcohol. It was then dried in an air-bath.

In the first experiments it was treated with hot water, and the amount of barium sulphate precipitated from the filtrate was calculated as percentage of sulphur in $0.50 \mathrm{~g}$ rubber.

XXX. Washed 0.200-gram portions of $\mathrm{PbSO}_{4}$ on filters. Each time $250 \mathrm{cc}$ hot water was used. The filtrates were slightly acidified with $\mathrm{HCl}$, and precipitated with $\mathrm{BaCl}_{2}$.

$$
\text { Sulphur } \quad 0.24 \quad 0.25
$$

These precipitates contained only traces of lead.

XXXI. Treated 0.200-gram portions of $\mathrm{PbSO}_{4}$ according to Hübener's method, slightly modified. Treated with I 3 cc conc. $\mathrm{HNO}_{3}$, evaporated practically to dryness on the steam-bath, added $50 \mathrm{cc} \mathrm{H}_{2} \mathrm{O}$, and $0.5 \mathrm{cc} \mathrm{Br}$ and 2 cc of dilute $\mathrm{HNO}_{3}(\mathrm{I}: 4)$. Heated, filtered, and washed with about $200 \mathrm{cc}$ of hot water. Then precipitated with $\mathrm{BaCl}_{2}$.

$$
\begin{array}{llll}
\text { Sulphur } & 0.73 & 0.80 & 0.57
\end{array}
$$

These precipitates contained a little lead. 
From these determinations it seems quite certain that the larger part of the sulphur found as soluble sulphate under XII must have come from the solution and decomposition of lead sulphate first formed when the rubber was attacked by nitric acid.

At the suggestion of Dr. Hillebrand, four determinations were made of the amount of lead carried down with the barium sulphate precipitated in the usual way from the aqueous extract of the fusion mass. In spite of the presence of a large excess of sodium carbonate, some lead goes into solution. The preliminary treatment was according to XVIII, and $2 \mathrm{~g}$ of rubber instead of $0.50 \mathrm{~g}$ was taken each time.

XXXII. After fusion, the melts were dissolved in water. To each of the first two there was added $2 \mathrm{~g}$ of sodium bicarbonate in order to decompose any alkali plumbate. The solutions were heated on the steam-bath for one and one-half hours and then filtered from the insoluble. After acidifying with hydrochloric acid, barium sulphate was precipitated in the usual way.

\begin{tabular}{lllcl} 
& \multicolumn{1}{c}{$\mathrm{I}$} & \multicolumn{1}{c}{2} & \multicolumn{1}{c}{3} & \multicolumn{1}{c}{4} \\
$\mathrm{BaSO}_{4}$ found (g) & 0.5379 & 0.5395 & 0.5437 & $0.54 \mathrm{I} 7$ \\
Sulphur (per cent) & 3.69 & $3.7 \mathrm{I}$ & 3.73 & 3.72
\end{tabular}

The barium sulphate precipitates were then mixed with soda and potash and fused. The melts were dissolved in water, filtered, and the residues washed with hot, very dilute sodium carbonate solution. The residues of barium carbonate and lead oxide were then dissolved in dilute nitric acid and the lead precipitated from the cold solutions by hydrogen sulphide. After standing over night in stoppered flasks, the precipitates of lead sulphide were filtered off, washed, dissolved in nitric acid, and finally converted into sulphate by evaporating down in porcelain crucibles with sulphuric acid and gently igniting.

$\mathrm{PbSO}_{4}$ found $(\mathrm{g})$

Equivalent to $\mathrm{BaSO}_{4}$ (g)

Corrected $\mathrm{BaSO}_{4}$ (g)

Corrected sulphur (per cent)

\begin{tabular}{cccl}
\multicolumn{1}{c}{ I } & \multicolumn{1}{c}{2} & \multicolumn{1}{c}{3} & \multicolumn{1}{c}{4} \\
0.0086 & $0.007 \mathrm{I}$ & 0.0040 & 0.0045 \\
0.0066 & 0.0055 & $0.003 \mathrm{I}$ & 0.0035 \\
0.5359 & 0.5379 & 0.5428 & 0.5407 \\
3.68 & 3.69 & 3.73 & $3.7 \mathrm{I}$
\end{tabular}


It is quite evident from these figures that although notable quantities of lead sulphate are carried down with the barium sulphate, the correction in the percentage of sulphur is negligible.

The filtrates from the original precipitates were treated with hydrogen sulphide and gave slight precipitates. The alkaline filtrates from the barium carbonate and lead oxide were tested with ammonium sulphide and became browri. The next day there was a slight film of a dark color on the bottom of each of the beakers in which these solutions were tested. This was probably a mixture of small amounts of lead and iron sulphides. In all the solutions tested, as well as in the actual determinations of lead sulphate, greater amounts of lead were found in I and 2, which had been treated with bicarbonate. Apparently at the temperature of the steam-bath the lead bicarbonate probably formed was not decomposed.

\section{CONCLUSIONS}

Treatment of the rubber with nitric acid alone gives low results. (Compare XV with XVIII.) This is probably largely due to loss of free sulphur, since nitric acid alone does not completely oxidize sulphur to sulphuric acid in the length of time ordinarily taken for a determination.

The Hübener method can not be employed in the presence of mineral fillers which tend to form insoluble sulphates. This applies especially to barium carbonate and litharge.

A comparison of XX to XXVII shows that the fusion method gives results very close to those obtained by direct precipitation and by neutralization. The van't Kruys method gives high results.

The best results seem to be obtained by the use of method XVIII, according to which the rubber is decomposed by means of nitric acid saturated with bromine.

WASHINGTON, July I9, I 9 I I. 